formation to a new allotropic form usually commences at a much lower temperature than the thermodynamically defined transition point, and in this 'transition interval' the specific heat of the metal increases very rapidly with the temperature, often reaching extremely high values.

In passing through the transition point, either by heating or by cooling, the allotropic changes are frequently accompanied by certain retardation phenomena. For example, beryllium, which has been given a preliminary heating at temperatures of $450^{\circ} \mathrm{C}$. or more and is then allowed to cool from $400^{\circ} \mathrm{C}$., gives off the same amount of heat, but over a longer period, than a sample of the metal which has not been heated above $400^{\circ} \mathrm{C}$. The change in the internal state of the metal brought about by the preliminary heating may persist for several months, but there is a continuous return to the original state. Similar changes have been observed with rhodium, zirconium, chromium, titanium, and other metals, and the phenomenon appears to be a very general one. It is interesting to note that in.the case of beryllium, the retardation of heat evolution com. pletely disappears if the sample of metal is previously finely powdered.

Another factor of importance is the remarkable influence which may be exerted by almost imper. ceptible traces of gases-chiefly of oxygen, but occasionally also of nitrogen and of hydrogen-on the phase changes which occur in metals. In the $\alpha$-titanium $\rightleftarrows \beta$-titanium transition, for example, there is at the transition temperature of $882^{\circ}$ an additional hysteresis effect, which disappears with a sample of metal prepared in vacuo, but returns on the addition of traces of oxygen and nitrogen.

Prof. Jaeger's experimental study of the specific heats of metals at different temperatures has provided more accurate data which can be applied to testing the validity at high temperatures of two important theoretical deductions. According to the quantum-theoretical treatment by Einstein and by Debye of the variation of the specific heat of solid substances with temperature, the atomic heat at constant volume of solid mono-atomic elements should, even at the highest temperatures, never exceed a value of $3 R=5 \cdot 955$ cal. The experimental results make it improbable, however, that any such upper limit exists, since this value is already ex. ceeded in most cases at relatively low temperatures. The second application concerns the validity of the Neumann-Kopp law, which states that the molecular heat of a compound is an additive property of the atomic heats. Prof. Jaeger's measurements show that, in the case of alloys, the law is obeyed only when true solid solutions are formed between the component metals. With intermetallic compounds, the deviations from additivity, which are sometimes very considerable, may be either positive or negative, and in all cases rapidly increase with the temperature of observation.
O. J. WALKER.

\title{
Insect Pests of Crops in England*
}

$\mathrm{T}$ 'HE Ministry of Agriculture and Fisheries' report for 1932-34 on insects affecting crops has been drawn up by Mr. J. C. F. Fryer, in collaboration with his colleagues at the Plant Pathological Laboratory, Harpenden. In dealing with advances in the applica. tion of insecticidal measures, the subject of pyrethrum is again considered in this report. Methods for the evaluation of the toxic principles of pyrethrum, elaborated by Dr. F. Tattersfield at the Rothamsted Station, have proved valuable, and it has been further shown that the incorporation of certain antioxidants greatly retards the deterioration of pyrethrum dust when exposed to the air. The plant has been shown to grow, and to yield satisfactorily, under English conditions; but the available methods of harvesting entail too heavy labour costs to warrant cultivation as a paying proposition. This aspect, therefore, remains in abeyance, at any rate for the time being, but in view of the valuable properties of pyrethrum, and the safety attending its application as a spray fluid, we may hope that cultural difficulties will eventually be overcome.

The hot-water treatment of daffodil bulbs as a measure against the Merodon fly and nematode pests is now an established procedure, and the same method has now become applicable in respect to the Tar. sonemus mite of the strawberry. The treatment has been further developed with reference to strawberries, chrysanthemums and violets.

Among introduced pests, the Colorado potato

* Ministry of Agriculture and Fisheries. Bulletin No. 99 : Report on Insect Pests of Crops in England and Wales, 1932-1934. Pp. vi +50 . (London: H.M. Stationery Office, 1936.) 18, net. beetle is of great importance : the recent eradication of a slight infestation in the Tilbury-Gravesend area is a matter for congratulation to all concerned. But for the prompt measures put in force by the Ministry, this insect might have gained a foothold, and led to a veritable campaign for its eradication. The extent of its adopted area in France, and its continued spread in that country, will serve as a justification for the close scrutiny that is being maintained at likely English ports of ingress.

Among other foreign pests that have found entry into Great Britain, reports on the eradication of the chrysanthemum midge and fluted scale are satisfactory, and measures to preclude the introduction of the apple maggot and cherry fruit fly have given the effective results anticipated. During the period under review, many indigenous crop pests are men. tioned. There were no very outstanding attacks on cereals but with regard to potatoes, the Heterodera eelworm was a serious menace and appeared to be spreading. Larvæ of chafer beetles were specially in evidence as pests of grassland, while in connexion with sugar beet cultivation, the discovery of the Heterodera potato eelworm in that crop has complicated the situation. Proper rotation and clean cultivation may avert the severe losses which this creature has brought about on the continent of Europe. Brassica crops came in for heavy infestation by the aphis Brevicoryne, flea beetles and the cabbage white fly - dry weather conditions seemingly having favoured such attacks.

Fruit pests are always numerous : the apple sawfly attracted most attention, but the application of 
proper measures, when carefully timed, reduced the menace to manageable proportions. The deterioration of strawberries has greatly concerned growers, and the discovery that the disease known as 'yellow edge' is carried by a prevalent species of aphis has added to the importance of the latter as a pest. Among glass-house troubles, the record of damage to tomato seedlings by a species of the order Symphyla during the three successive years under review is of interest. Much damage has been claimed as being due to such creatures in America in recent years, but the status of this species as a pest is not as yet universally accepted.

The report concludes with a useful bibliography of publications bearing upon the subjects dealt with.

A. D. I.

\section{The Marine Steam Boiler}

$I^{N}$ a recent note on "The Future of Steam Propulsion", reference was made to a paper on the relative merits of steam and oil engines for ships (NATURE, 137, 267; 1936). The subject is one of considerable importance at the present time, when a period of increased ship construction is imminent, and a new and different 'battle of the boilers' such as occurred at the time of the introduction of the water-tube boiler into H.M. Navy may be anticipated. Two papers dealing with the matter were read before the spring meeting of the Institution of Naval Architects in April last. In one of these, a "Review of the Present Position of Marine Steam Boilers", Eng.Rear-Admiral W. M. Whayman dealt with large highspeed ocean-going mail steamers and passenger liners; he holds that these services constitute practically an exclusive field for steam machinery. Asserting that oil is, at present, the only suitable fuel for such installations, he points to the fact that, where speed and passenger comfort are the main consideration, oil-fired water-tube boilers have been adopted for ocean liners in all countries, and he gives details of the boiler equipment of many well-known ships. Whereas pressures on shore approach 1,500 lb. per sq. inch at $900^{\circ} \mathrm{F}$. the tabulated figures show that $400-450 \mathrm{lb}$. per sq. in. and $650^{\circ}-740^{\circ} \mathrm{F}$. con stitute the generally accepted limits for high-class sea installations at present. It is suggested that by reason of the more severe conditions of sea service, these pressures and temperatures may be expected to remain fairly steady. It should, however, be recognized that since these special sea conditions must always exist, marine practice, while necessarily following land practice at a safe distance, will steadily advance as quickly as new methods, machinery and means of operation have been proved to be sufficiently reliable for service at sea.

The water-tube boiler, by reason of the much smaller diameters used as compared with the Scotch type, has enabled pressures to be nearly doubled, and the present tendency towards the elimination of the drum makes possible further advances in working pressures. Towards this end also the use of higher tensile alloy steels, the adoption of welding processes, the provision of air heaters, and the introduction of forced circulation, of pure feed supply and of methods of treating the steam between the turbines either by re-heating or by extraction of moisture, indicate the lines on which improvements may be anticipated.

In "Naval Water-tube Boilers", Eng.-Capt. S. R. Dight gave particulars of tests and experiments which have been carried out at the Admiralty Fuel Experimental Station, Haslar, with the object of obtaining more intimate information regarding the internal working conditions, and so enabling further improvements in efficiency and reliability to be made. Circulation was tested by means of Pitot tubes, and marked variations were noted between differently placed tubes, with occasional reversals occurring in fire-row tubes when sudden changes took place in the feed supply.

A device described as a circulation augmenter was introduced to enable the feed supply to assist circulation, and proved advantageous. The overheating of fire-row tubes, the use of air pre-heaters and of automatic feed regulators were among the subjects of test, and the general conclusion was that increase of output for the same space and weight was possible. The application of forced circulation is stated to be under consideration.

\section{Breeding of Arctic Marine Prosobranchs*}

\footnotetext{
$\mathrm{D}^{\mathrm{n}}$ R. GUNNAR THORSON accompanied the Danish Three-Year Expedition to East Greenland in 1931-34 under the leadership of Dr. Lange Koch, and made extensive and regular collections of plankton from the southern main station of Ella Island during the period from January until September 1932. Later, these samples were supplemented by others collected by a Greenlander, Benjamin Samuelsen; thus giving a whole annual cycle of East

* "Studies of the Egg-Capsules and Development of Arctic Marine Prosobranchs" by Gunnar Thorson. Treaarsexpeditionen til Christian den X's Land 1931-1934 under Ledelse af Lange Koch. Medd. om Gronland, 100, No. 5 (1935).
}

Greenland plankton. In none of these samples and in none previously examined from these regions were there any prosobranchiate gastropods. This remarkable fact was partially explained by the large number of different prosobranchiate egg capsules with big embryos in the bottom samples and dredged material.

In order to investigate further, Dr. Thorson con. tinued the collecting of gastropod egg-masses in 1932 and during the cruise of the Godthaab in the summer of 1933, and in addition examined material from other expeditions. By carefully studying the species in their various habitats and their distribution, and 